\title{
Modeling Metadynamic Recrystallization of a Die Steel during Ingot Breakdown Process
}

\author{
Kanwal Chadha , Davood Shahriari and Mohammad Jahazi \\ Department of Mechanical Engineering, École de Technologie Supérieure, Montréal, Canada
}

\begin{abstract}
Ingot forging processes often consist of several successive deformation steps with high interpass times, during which metadynamic recrystallization (MDRX) occurs. Two-stage isothermal compression tests were carried out at $1150^{\circ} \mathrm{C}$ and $1200^{\circ} \mathrm{C}$ with strain rates of $0.25-2 \mathrm{~s}^{-1}$ and interpass times of $5-25 \mathrm{~s}$. Based on the experimental results, a material model for MDRX is proposed. The constitutive model was implemented in Forge NxT $1.1^{\circledR}$ software to simulate the multistage compression. Results from the material model are consistent with the numerical analysis and experimental results.
\end{abstract}

\section{Introduction}

Forging of ingot after casting process starts with ingot breakdown process which is generally performed at very high temperatures $\left(0.75\right.$ of melting point $\left." \boldsymbol{M}_{P}{ }^{\prime \prime}\right)$ so as to breakdown the chemical (macrosegregation) and microstructural structure (as-cast dendritic) inhomogeneity [1]. The forging process usually consists of various deformation passes which includes interpass periods between deformations. During interpass periods, dynamic recovery [2], static recrystallization [3] and metadynamic recrystallization [4-7] may occur. Hot workability is defined as the amount of deformation that a material can undergo without cracking and reach desirable mechanical properties and microstructure at a given temperature and strain rate. It is generally evaluated by various parameters like strain rate, strain, temperature and interpass time. It is therefore a challenging task to determine the optimum thermomechanical route to apply in order to achieve the desired mechanical property keeping in view the microstructural changes and softening mechanisms involved. Kinetic equations are often used to describe the plastic flow properties of metals and alloys. Many research groups have attempted to develop kinetic equations using Avrami equation to describe the flow behavior of various alloys using experimental data $[5,8-10]$. Despite large efforts being made on the development of kinetic equations for wrought ferrous alloys, little information is available on the flow behavior of as-cast structures at very high temperature $\left(\sim 0.7 \mathrm{M}_{\mathrm{p}}\right)$ and prolonged interpass times. This corresponds to the ingot breakdown process during which the porosities inherited from solidification are close, macrosegregation levels are reduced and the ascast structure is converted into a much finer and more isotropic wrought structure. The objective of this study is to investigate the influence of strain rate, temperature and interpass time on compressive deformation characteristics of as-cast $42 \mathrm{CrMo}$ using double hit hot compressive tests. Avrami equation describing the relationship of flow stress, strain rate, strain, interpass time and temperature was investigated and used to simulate real time analysis of the ingot breakdown process using FEM analysis.

\section{Experimental}

The composition of the as-cast $42 \mathrm{CrMo}$ high strength steel is shown in Table 1. The specimens were provided by Finkl Steel Co., Sorel Tracy, Quebec, Canada. Cylindrical specimens were machined with a diameter of $10 \mathrm{~mm}$ and a height of $15 \mathrm{~mm}$. Hot compression tests were performed in Gleeble $\mathrm{e}^{\mathrm{TM}} 3800$ Thermomechanical Simulator at temperatures of $1150^{\circ} \mathrm{C}$ and $1200^{\circ} \mathrm{C}$, strain rates of $0.25,0.5$, and $2 \mathrm{~s}^{-1}$ and interpass times of 5,15 and $25 \mathrm{~s}$. The heating rate was $2^{\circ} \mathrm{C} / \mathrm{s}$ till $1260^{\circ} \mathrm{C}$ where it was maintained for $300 \mathrm{~s}$ so as to get homogenous temperature over the specimen. The specimen was then cooled to a respective deformation temperature at a cooling rate of $1^{\circ} \mathrm{C} / \mathrm{s}$. Water quench was done at the end of the deformation so as to freeze the microstructure.

Table 1: Composition of as-cast 42CrMo (Wt. \%)

\begin{tabular}{ccccccc}
\hline $\mathrm{C}$ & $\mathrm{Mn}$ & $\mathrm{Si}$ & $\mathrm{Mo}$ & $\mathrm{Cr}$ & $\mathrm{Ni}$ & Other \\
\hline 0.35 & 0.85 & 0.40 & 0.45 & 1.85 & Added & Microalloying \\
\hline
\end{tabular}




\section{Results and Discussions}

\subsection{Flow Stress-Strain Curves}

For the present report, results from deformation temperature of $1200^{\circ} \mathrm{C}$ at strain rate of $0.25 \mathrm{~s}^{-1}$ and interpass times of 5, 15 and $25 \mathrm{~s}$ are considered. Stressstrain curve of double hit hot compression tests (Figure 1) reveals that the yield flow stress of the second hit is higher than that of the first hit deformation. It can be seen that in the second hit, the yield flow stress generally decreases with the increase in the interpass time. The results point out a fact that metadynamic softening increases with an increase in the interpass time. It is interesting to note that at interpass time of $25 \mathrm{~s}$, much of the metadynamic softening has taken place and the value of the yield flow stress of the second hit deformation is very close to the yield flow stress of the first hit deformation. This behavior can be explained by the fact that the dislocation density decreases with an increase in the interpass time. This results in low yield flow stress during second hit deformation [5].

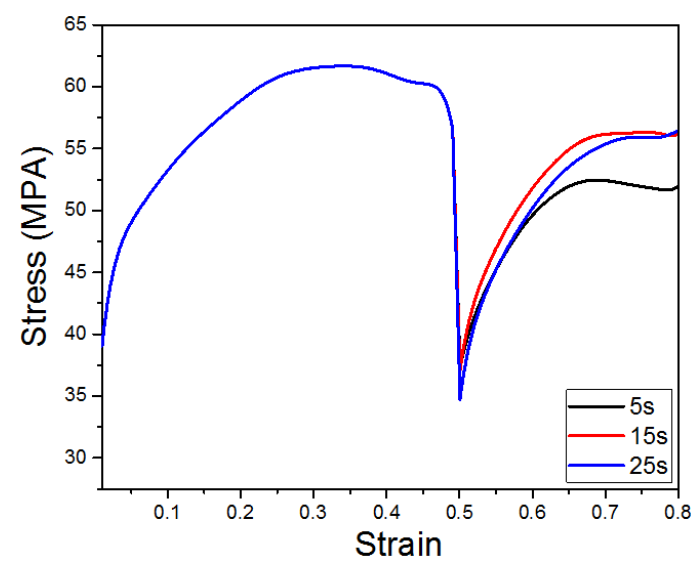

Figure 1. Flow stress strain curves in double hit hot compression at a temperature of $1200^{\circ} \mathrm{C}$ and strain rate of $0.25 \mathrm{~s}^{-1}$.

\subsection{Effect of Temperature on Metadynamic Softening}

The metadynamic softening fraction $X$ is determined by taking $0.2 \%$ offset-stress method. The value of $X$ is calculated by:

$X=\frac{\sigma_{m}-\sigma_{2}}{\sigma_{m}-\sigma_{1}}$

where $\sigma_{m}(\mathrm{MPa})$ is the flow stress at the end point in the first hit deformation, $\sigma_{1}(\mathrm{MPa})$ and $\sigma_{2}(\mathrm{MPa})$ are the offset yield flow stress for the first and second hit compression respectively.

The effect of temperature at the strain rate of $0.25 \mathrm{~s}^{-1}$ is shown in Figure 2. It can be seen that with an increase in temperature, the metadynamic softening fraction increases. For different temperatures $\left(1200^{\circ} \mathrm{C}\right.$ and $1150^{\circ} \mathrm{C}$ ) and interpass time of $15 \mathrm{~s}$, the metadynamic softening fraction values are $69.5 \%$ and $57.2 \%$, respectively. This is due to the fact that, increase in the deformation temperature causes an increase in the diffusion of the atoms which make migration of the boundaries easier thereby benefitting the growth of the dynamically formed grains [10].

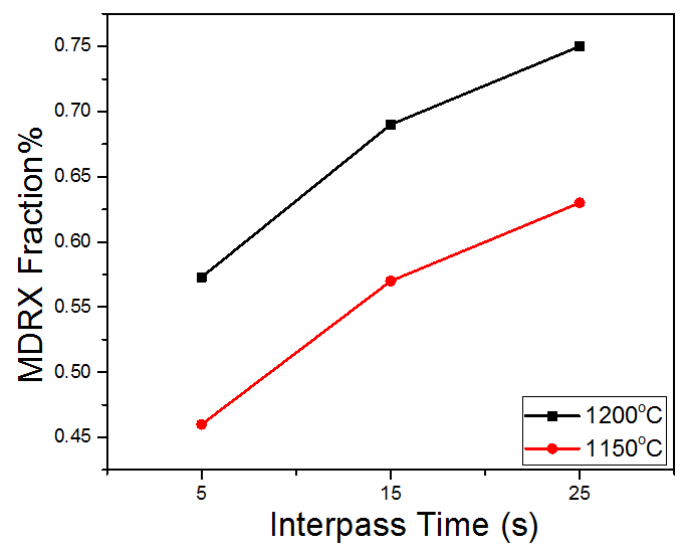

Figure 2. Effect of deformation temperature on metadynamic softening.

\subsection{Kinetic Equation of Metadynamic Recrystallization}

In order to characterize the metadynamic softening behavior of as-cast $42 \mathrm{CrMo}$ steels, the Avrami equation is applied. The equation is in the following form:

$X_{m}=1-\exp \left[-0.693\left(\frac{t}{t_{0.5}}\right)^{n}\right]$

Where $X_{m}$ is the metadynamic softening fraction (\%), $t$ is the interpass time (s), $n$ is the material dependent constant, $t_{0.5}$ is the time for metadynamic softening fraction of $50 \%$ (s) which is expressed as:

$t_{0.5}=A \dot{\varepsilon}^{p} \exp \left(\frac{Q_{m}}{R T}\right)$

where, $Q_{m}$ is the activation energy for metadynamic recrystallization $\left(\mathrm{KJmol}^{-1}\right), \quad T$ is the absolute deformation temperature $\left({ }^{\circ} \mathrm{K}\right)$, and $R$ is the universal gas constant $\left(\mathrm{Jmol}^{-10} \mathrm{~K}^{-1}\right), \quad p$ and $A$ are the material dependent constants.

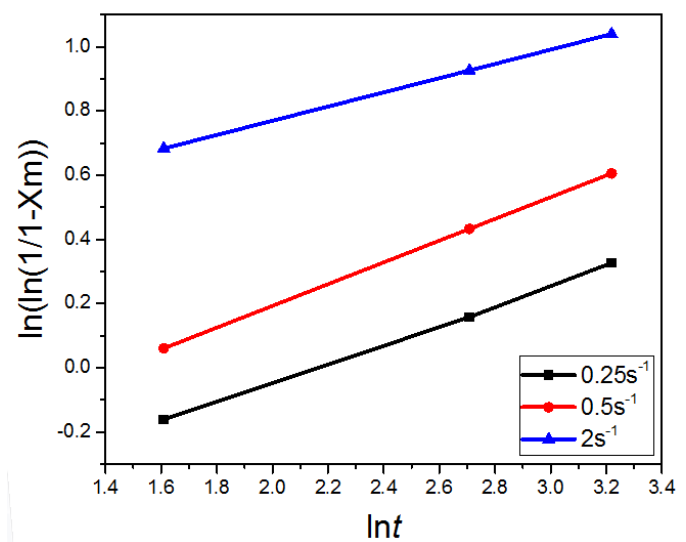

Figure 3. Relationship between $\ln (\ln (\mathbf{1} / \mathbf{1}-\mathrm{Xm}))$ and $\ln \boldsymbol{t}$ at deformation temperature of $1200^{\circ} \mathrm{C}$. 
The values of $t_{0.5}$ and $n$ in Eq. (2), A, $Q_{m}$ and $p$ in Eq. (3) were calculated by linear regression method presented in Figures 3 and 4 and as described in various published papers $[5,9,10]$.

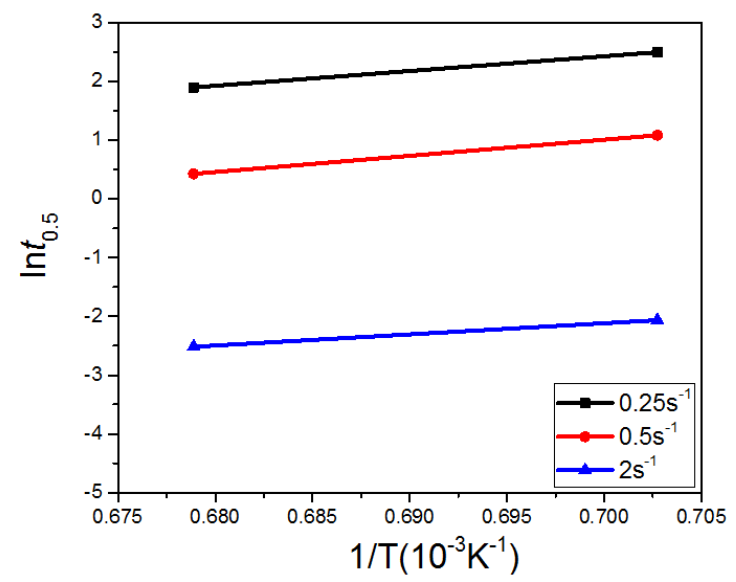

Figure 4. Relationship between $\ln t_{0.5}$ and $1 / T$.

The values of the constants calculated using linear regression method are shown in Table 2.

Table 2: Values of constants derived from the regression analysis

\begin{tabular}{cccc}
\hline $\boldsymbol{n}$ & $Q_{m}$ & $p$ & $\operatorname{LnA}$ \\
\hline 0.27 & 185853 & -0.318 & -2.019 \\
\hline
\end{tabular}

The equations of metadynamic softening fraction and the time for $50 \%$ softening for as-cast $42 \mathrm{CrMo}$ steels are represented as follows:

$$
\begin{aligned}
& X_{m}=1-\exp \left[-0.693\left(\frac{t}{t_{0.5}}\right)^{0.27}\right] \\
& t_{0.5}=0.1328 \dot{\varepsilon}^{-0.318} \exp \left(\frac{185853}{R T}\right)
\end{aligned}
$$

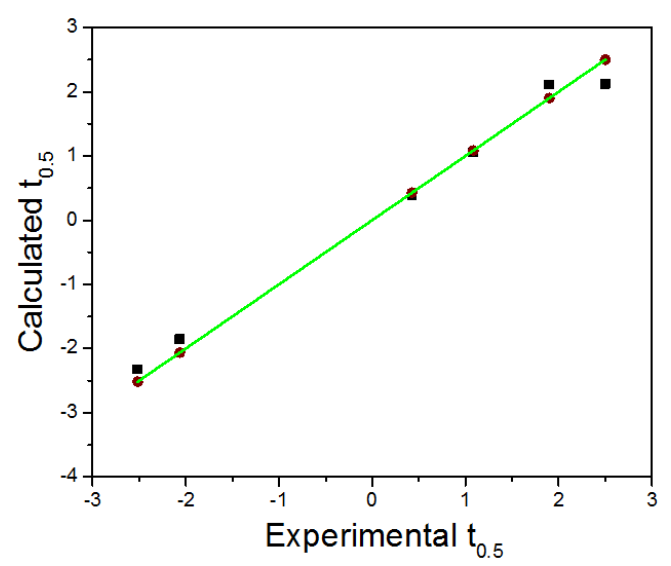

Figure 5. The comparison of the calculated and experimental $t_{0.5}$. Green line with brown symbols represent experimental values and black symbols represent calculated values.
The comparison of the experimental and calculated $t_{0.5}$ at various deformation parameters is shown in Figure 5. The calculated results are in good agreement with the experimental results, thereby confirming that the kinetic equation is able to predict the model for metadynamic behavior of as-cast 42CrMo steel.

\subsection{FEM Simulation for Recrystallization Behavior of $42 \mathrm{CrMo}$}

In this study, the Forge NxT $1.1^{\circledR}$ software is used to carry out FEM simulation of hot compression of cylindrical specimen. An eighth of the $3 \mathrm{D}$ model is considered instead of a whole geometry to simulate the hot compression test because of the symmetrical features of the specimen, saving the computational time and getting the sufficient accuracy. The tetrahedral element is used to discrete the geometry model.

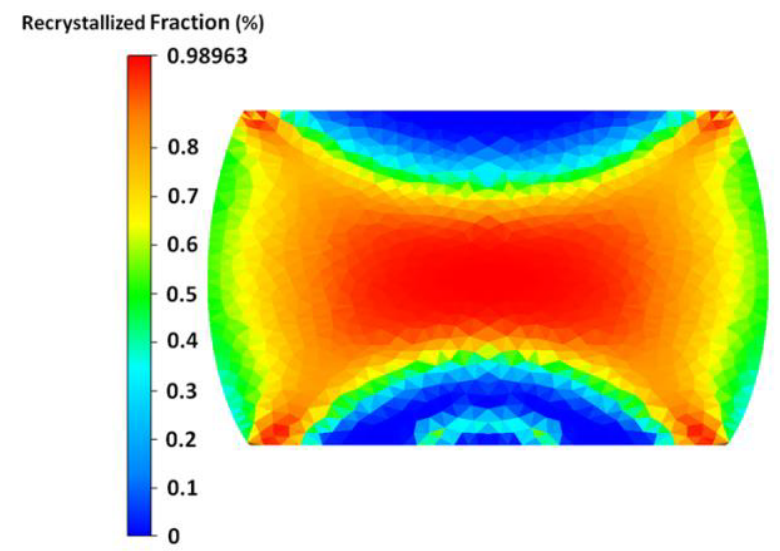

(a)

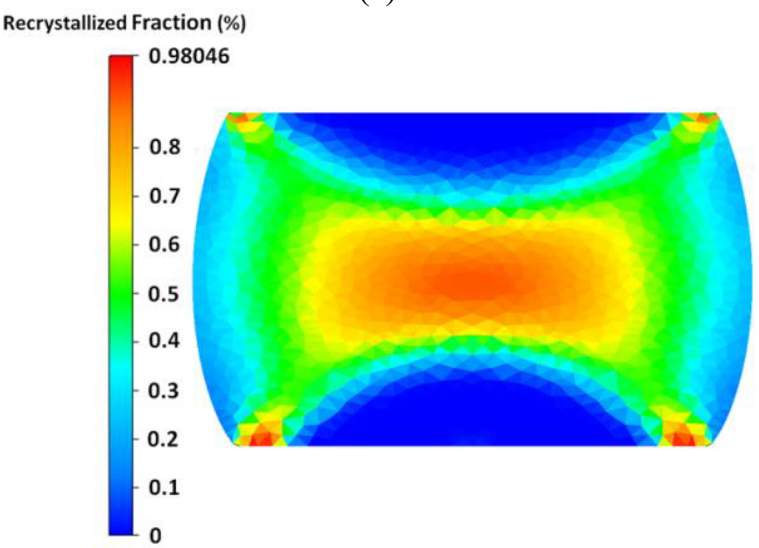

(b)

Figure 6. FEM simulation results of recrystallization fraction distribution under $1200{ }^{\circ} \mathrm{C}$ at the strain rate of (a) $0.25 \mathrm{~s}^{-1}$ and (b) $2 \mathrm{~s}^{-1}$.

The upper die moved along the central axis of model while both upper and lower dies are set as a rigid body. The friction coefficient between the dies and the sample is assumed as 0.4. Since the sample is very small and its heating during hot compression by Gleeble ${ }^{\mathrm{TM}} 3800$ is in accordance with the accurate temperature control resistance heating method, an adiabatic heating condition is imposed in this simulation. Physical and 
thermo-physical properties are critical parameters for any hot deformation simulations. So, the material property data (as a function of temperature) are calculated by JMatPro ${ }^{\circledR}$ and then directly input into the FEM code. The implementation of the flow stress constitutive equations of as-cast $42 \mathrm{CrMo}$ steel according to Arrhenius constitutive model [11] and the recrystallization model in the FEM software are accomplished by user subroutine. Figure $6(\mathrm{a} \& \mathrm{~b})$ represents total recrystallization (RX) fraction under $1200^{\circ} \mathrm{C}$ at different strain rate. The recrystallization fractions in the center of the specimen under $1200^{\circ} \mathrm{C}$ at strain rate $2 \mathrm{~s}^{-1}$ nearly achieve $90 \%$. It can be seen that the recrystallized zone will enlarge as the strain rate reduces.

According to Figure 7, recrystallization region with strain rate $0.25 \mathrm{~s}^{-1}$ at $1200^{\circ} \mathrm{C}$ in the center is almost complete $(100 \%)$ and the size of this zone is approximately with a diameter $3 \mathrm{~mm}$ and a length of $1.5 \mathrm{~mm}$.

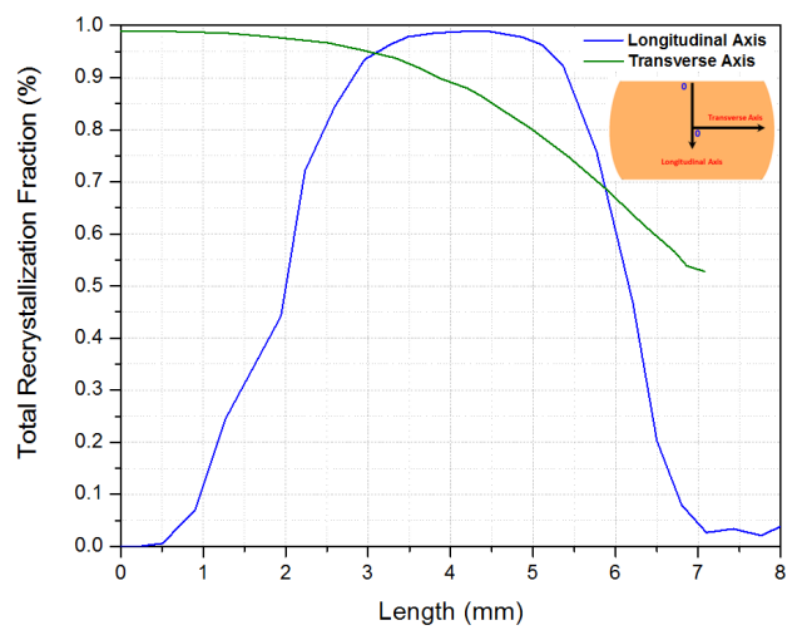

Figure 7. Predicted recrystallized region in the deformed specimen under $1200^{\circ} \mathrm{C}$ at the strain rate of $0.25 \mathrm{~s}^{-1}$.

Total recrystallization volume fraction of as-cast 42CrMo steel by FEM simulation under various strain rates at deformation temperature $1200^{\circ} \mathrm{C}$ is illustrated in Figure 8.

It shows the total volume fraction of recrystallization increases with the increasing of the strain. It approves at lower strain rate total RX fraction tends to be complete and close to $100 \%$. The main reason for this phenomenon is that higher strain rates lead to increase work hardening rate and decrease the time for recrystallization. So, the recrystallized nucleus at high strain rate has no enough time to fully grow up. Finally, there is a good agreement between the predicted value by FEM simulation results and the experimental data.

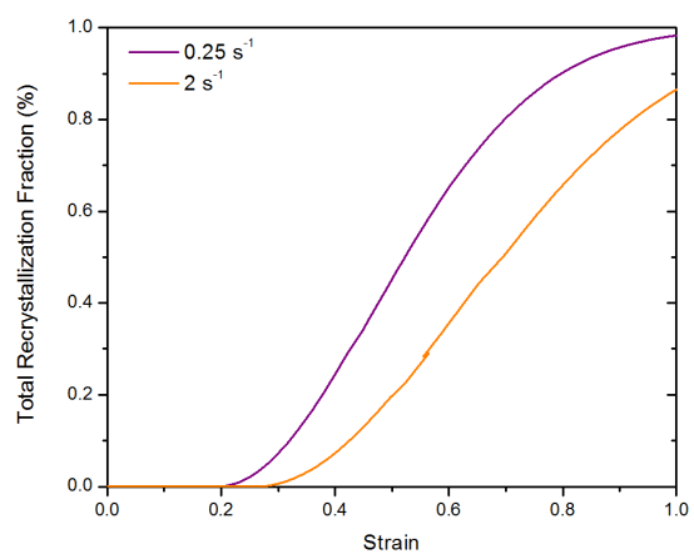

Figure 8. Volume fraction of total recrystallization fraction at the center of the deformed sample under $1200^{\circ} \mathrm{C}$ at the strain rate of $0.25 \mathrm{~s}^{-1}$ and $2 \mathrm{~s}^{-1}$.

\section{Conclusions}

Double hit hot compression tests of as-cast $42 \mathrm{CrMo}$ steel was conducted using Gleeble ${ }^{\mathrm{TM}} 3800$ Thermomechanical Simulator. Deformation temperature of $1200^{\circ} \mathrm{C}$ and $1150^{\circ} \mathrm{C}$, strain rates of $0.25,0.5$ and $2 \mathrm{~s}^{-1}$ and interpass times of 5,15 and $25 \mathrm{~s}$ were selected so as to investigate the effect of deformation parameters on metadynamic recrystallization. Using experimental conditions, the Avrami equation was obtained to characterize the metadynamic behavior. The following are the main conclusions of the research:

a. With an increase in temperature, strain rate and interpass time, the metadynamic softening fraction increased.

b. Maximum metadynamic softening occurs at temperature of $1200^{\circ} \mathrm{C}$ at an interpass time of $25 \mathrm{~s}$.

c. Avrami equation developed is in good agreement with the experimental and calculated results.

d. Integrating with the material kinetic models in the Forge NxT $1.1^{\circledR}$ software is developed to analyze the microstructure evolution under various hot deformation conditions.

\section{Acknowledgements}

The authors are very much grateful to Finkl Steel Co. for providing the specimens for the present research. The authors are also grateful to NSERC for their support in the framework of a Collaborative Research and Development project (CRD), and Transvalor Americas Corp for providing Forge NxT $1.1^{\circledR}$ software.

\section{References}

1. Dieter, G.E., H.A. Kuhn, and S.L. Semiatin, Handbook of Workability and Process Design. 2003: Asm International.

2. McQueen, H.J. and J.J. Jonas, in Treatise on Materials Science \& Technology, A. R.J, Editor. 1975, Elsevier. p. 393-493. 
3. Lin, Y.C., M.-S. Chen, and J. Zhong,

Computational Materials Science, 2008. 44(2): p.

316-321.

4. Gao, F., et al., Materials Science and Engineering: A, 2000. 277(1): p. 33-37.

5. Lin, Y.C., M.-S. Chen, and J. Zhong, Journal of Materials Processing Technology, 2009. 209(5): p. 2477-2482.

6. Zhou, L. and T. Baker, Materials Science and Engineering: A, 1995. 196(1): p. 89-95.

7. Beladi, H., P. Cizek, and P.D. Hodgson, Acta Materialia, 2011. 59(4): p. 1482-1492.

8. Cho, S.-H. and Y.-C. Yoo, 2001. 36(17): p. 42794284.

9. Elwazri, A., E. Essadiqi, and S. Yue, ISIJ international, 2004. 44(4): p. 744-752.

10. Liu, J., et al., Materials Science and Engineering: A, 2013. 565: p. 126-131.

11. K. Chadha, D.Shahriari, M. Jahazi, La Metallurgia Italiana - International Journal of the Italian Association for Metallurgy, 2016. 4: p. 5-12. 